\title{
Run for the Group: The Impacts of Offline Teambuilding, Social Comparison and Competitive Climate on Group Physical Activity - Evidence from Mobile Fitness Apps
}

\author{
Yuan Zhang \\ University of Texas at Arlington \\ yuan.zhang@uta.edu
}

\author{
Jie Zhang \\ University of Texas at Arlington \\ jiezhang@uta.edu
}

\author{
Zilong Liu \\ Dongbei University of Finance \\ and Economics \\ zilonglord@126.com
}

\begin{abstract}
To encourage users to exercise more and to improve the retention, mobile fitness app developers build apps with more social interaction features on the collective level, such as allowing users to join groups to work out and holding offline group meetup events. However, literature has not provided a clear theory on the impacts of the within-group social comparison and between-group competitive climate on the participation in group exercises. Motivated by this gap, we build a conceptual framework to explain the empirical effects based on the Social Comparison theory. Based on the Teamwork theory, we also propose that offline group team building activities moderate the above relationships. We collect usage data from a mobile fitness app and conduct a series of comprehensive empirical analyses to test and validate the main and moderating effects. Our results show that both the within-group social comparison and the betweengroup competitive climate can improve group exercise participation. Additionally, the amount of offline activities moderates the main effects in opposite directions. Our findings help fitness app developers to better understand the impacts of offline team building activities on the participation of the online virtual groups, and further, we provide implications regarding how to make online community policies and design gamification incentive mechanism to stimulate and promote offline team building activities.
\end{abstract}

\section{Introduction}

Mobile fitness applications allow users to record exercise activities and self-regulate health conditions, and are found to help motivate people to work out more and live healthier (Zhou et al 2016). However, app developers found that only the recording function is not sufficient to engage and attract users and the retention rate drops while the initial passion fades out (Sonders and Ana L. 2016). Accordingly, fitness apps like Runkeeper, Keep and Nike+, etc. are enabling social interactions among users. The social interactions among individual users is verified (Wu et al 2015, Zhou et al 2016 and Munson and Consolvo 2012) to be able to further improve users' activity levels and overall health behaviors. Besides the integration with social media, many apps also allow users to create and join groups, communicate through online group pages, initiate, participate and record offline group meetups, and upload and share meetup pictures. Group members can observe the activity records of top runners, the activity records of group organizers, pictures and documents of group offline meetup events, the rank of the group and the overall activity records and performance of the group from the group board information. These stimuli might encourage the peers to exercise more

However, little is known whether this "group" concept and the offline social interactions are effective in motivating users to exercise more actively and often. Most prior research (Zhou et al 2016, Cavallo et al 2012 and Richardson et al 2010) focused on the individual level of social influence and comparison rather than on a collective level. Fewer researchers have studied the role of offline group member social interactions, such as team-building events, on the social comparison effects on an individual user's activity level. In response to the literature gap, we aim to examine the effects of fitness apps with group level social interactions on group user's physical activities by focusing on the following two research questions. (1). How do within-group social comparison and between-group competitive climates affect group activity performance? (2) How do offline team building activities moderate these effects?

To address these research questions, we build a conceptual model in Figure 1 by combining the Social Comparison theory and the Teamwork theory. 
According to the Social Comparison theory and within an exercise group, top performance members can be considered as an athlete role model and upward comparison benchmarks by other group members. The out-performed records can stimulate other members to exercise more active and more often. Since group organizers participate more frequently in group events and their records and information are more often exposed to other group members. As influencers, the exercise performance record of group organizers shall also have a significant impact in encouraging others to participate workout more. In general, the within-group social comparison affects group members' activity levels and can shape the group behavior (Kelman 1958, Mussweiler et al. 2004). This theory also demonstrates that environmental factors like competitive climate can have contingency impact on the effect of betweengroup comparison and consequently on the group level physical activity behavior (Brown et al. 2007 and We et al. 2005). Such competitive climates between groups can enlarge members' sense of "group" and amplify their focus on group task performance. The Teamwork theory, by Tuckman (1965), reveals that team building activities can improve social support and social ties and decrease social distance among colleagues who work in the same group. Team building or casual social events can thus enhance the group cohesion and motive co-workers to have better group task performance. We apply the proposition of the Teamwork theory to the online hobby-group setting and expect that the offline team building activities can moderate the effects of within-group social comparison and between-group competitive climate on group exercise participation.

We test our model with a private dataset of 152 groups for 38 weeks provided by an outdoor running app through the fixed effect baseline model, the moderation model, and Panel VAR model. We find that both the within-group social comparison and the between-group competitive climates significantly improve the group exercise participation. The number of offline activities has a significant positively moderation impact on the relationship between the between-group competitive climate metrics and group participation. However, the interactions between offline team building and within-group social comparison are not significant. The robustness and validation of analysis results are checked through different tests, and we conduct several additional analyses to examine the dynamic impacts of group level social comparison further.

This study contributes to the literature in several different ways. First, most research focusing on fitness apps apply the social comparison theory to explain users' behavioral patterns on the individual level.
We extend the social comparison theory to the group level and examine the role of "group" by differentiating the social comparison within group members and the comparison or competition between different groups. Second, in previous literature, group identity is examined as an environmental factor and measured mainly through surveying people's perceived belongingness. Our study provides direct empirical evidence to quantify the distinct consequences of within and between group social comparisons and competition. Third, there are few previous works studying the user's offline social interactions and their impacts on user's online retention and exercise participation. By combining the Teamwork theory, we explain distinctive moderating effects of offline teambuilding activities on the effects of within-group social comparison and between-group competitive climate. Fourth, we extend the generalization of the Teamwork theory from a working setting in the human resource field to an online-hobby-community setting in the IS field by verifying its central propositions through rich empirical evidence.

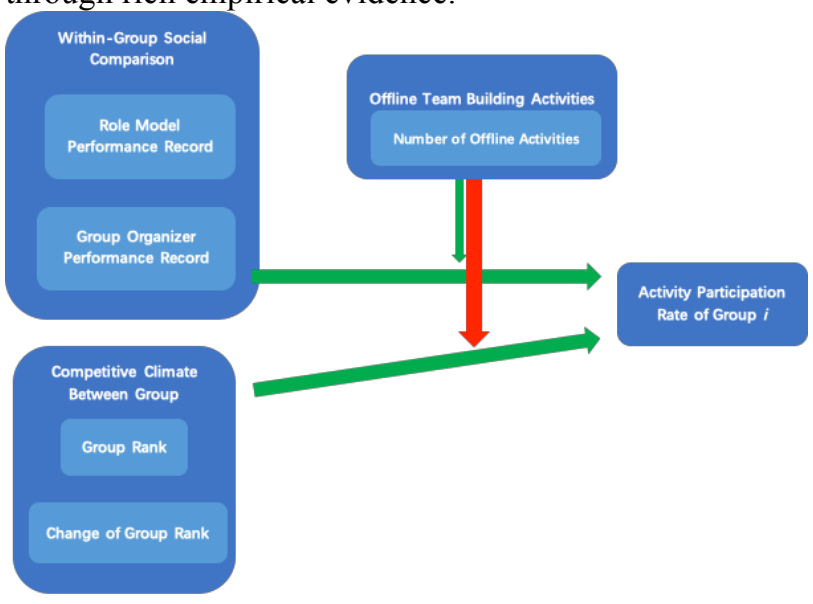

\section{Literature and Hypotheses Development}

\subsection{Within-Group Social Comparison}

When exercise with a group and are exposed to peer's performance from leaderboard information, there is a drive for users compare with others for accurate self-evaluation (Festinger 1965). Leaderboards, or the records of top-performance runner can be considered as desirable reference or standards for upward comparison. The high comparison standards can promote group behaviors like volunteering actions and coupling information seeking are found by previous research (Fisher and Ackerman 1998 and Bock and Kim 2002). In our research setting, the promoted outcomes could be doing more exercise and running a longer distance. Top-performance members 
can be considered to be athletes role models in upward comparison for the other group members with the aim of achieving better sports ability. Consequently, role model's records can encourage other group members to exercise more active and more often. Thereby, we propose

H1a: Role models (in terms of top 3 best performance members)'s activity records can significantly impact on the group exercise participation.

In online hobby groups, the function of a group organizer is to serve, operate and manage the virtual group. Their behaviors are more accountable and often exposed to other members (Breukele et al 2012). Their exercise record can also be an influential reference (Singer 1981). Therefore, we propose

H1b: Group organizer's activity records can significantly impact on the group activity performance.

\subsection{Between-Group Competitive Climate}

The affective consequences of social comparisons include coping and adaptive responses (Bunnk et al 1990 and Mussweiler 2000) to the discrepancy between outcomes of self-evaluation and that of targets. Research on social comparison theory like Garcia et al 2013, Wu et al 2015 and Sepehr and Head 2011 found that environmental factors like competitive climate can influence the consequence of social comparison through rank or leaderboard information on users' attitude and behaviors. In our research setting, the group identity can cohere member's attitudes and response to the competitive climate factors like group ranks and the change of the rank. Observing the group rank (the comparison results with other groups) may make members exercise more with the aim of changing the rank. Similarly, observing the change of the group rank may also motivate members to change their work out behaviors. Therefore, we propose the following:

H2a: The rank of a group can significantly impact on the group's activity performance;

H2b: The change of group rank can significantly impact on the group's activity performance.

\subsection{Offline Team Building Activities}

According to the team working theory by Tuckman (1965), team building activities can effectively enhance team member's sense of "togetherness" during the norming and performing stages of groups that are focusing on tasks. Cohesion, the sense of "togetherness" is verified to be associated with various positive individual and group consequences (Carron and Spink 1993). The consequences include reducing social distance and boosting social support among group members, relieving anxiety regarding interpersonal competitiveness within groups (Carron 1998), enhancing trust and feelings of security with group members, and improving the consensus to the high-performance reference and sense of responsibility for group outcomes etc. (Widmeyer and Williams (1991)). Under the fitness app research setting, team building activates are usually offline meetup events. The app allows users to initiate and record events as well as upload pictures later on. All records of offline events for the previous week are accessible and observable to all group members on the group board. We consider the weekly number of offline meetup events as the representation of offline team building and propose $\mathrm{H} 3$ as follows.

H3: The offline team building (in terms of the weekly number of offline meetup events) can significantly moderate the effects of within-group social comparison ( $\mathrm{H} 3 \mathrm{a})$ and the effects of betweengroup competitive climates $(\mathrm{H} 3 \mathrm{~b})$ on the group activity performance

\section{Research Context and Data Description}

Our research context is a fitness mobile application of outdoor runners. The application enable users record their activities, join or form virtual groups, start, participate and record offline meetups, upload and share meetup pictures etc. We choose this app because: First, by 2016 the app owns 80,000,000 active users. Its large user base can provide us sufficient observations and guarantee the sample representativeness and external validity of our research. Second, this app provides group level socialization and gamification features and this allows us to test our hypothesis on the group level.

The data sample is collected from the app and spans 38 weeks from August 12017 to April 292018. The sample includes 152 groups (5775 observations) in a four-season city- Dalian in China. We exclude groups whose size is less than 10 members and those were formed during our research time span.

\begin{tabular}{|c|c|c|}
\hline 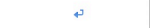 & Variable & Description \\
\hline $\begin{array}{c}\text { Exercise } \\
\text { Participation Rate }\end{array}$ & $D E \_A C T_{i, t^{2}}$ & $D E_{-} A C T_{i, t}=\frac{\text { Number of runnings of all members at week } t}{\text { Group size at } t * 7}$ \\
\hline \multirow{2}{*}{$\begin{array}{l}\text { Within-Group } \\
\text { Social comparison }\end{array}$} & NO_TOP $3_{i, t-1}$ & Role Model Records $=$ Average kilometers the top three members run at $t-1$ \\
\hline & NO_CAP $P_{i, t-1}$ & Group Organizer Records=Average kilometers the group organizer run at $t-1 \mathrm{t}$ \\
\hline \multirow{2}{*}{$\begin{array}{l}\text { Between-Group } \\
\text { Competitive Climate }\end{array}$} & $\operatorname{RANK}_{i, t-1}$ & The rank of the group at $t-1$ \\
\hline & $\triangle \mathrm{RANK}$ & $\triangle R A N K=R A N K_{i, t-1}-R A N K_{i, t-2}$ \\
\hline $\begin{array}{c}\text { Offline Team } \\
\text { Building Activities }\end{array}$ & NO_OFFACT $T_{i, t-1}$ & Number of offline meetup activities hold at $\mathrm{t}-1$ \\
\hline \multirow[t]{2}{*}{ Control variables } & SPORT_INDEX ${ }_{t}{ }^{3}$ & $\begin{array}{l}\text { Weather= A dummy variable to show whether it is safe and good for out-door } \\
\text { exercise }\end{array}$ \\
\hline & $L A G_{-} G_{-} B U I L D_{i, t}$ & Group Age- Number of weeks from the group was formed till t \\
\hline
\end{tabular}


Table 1 summarizes all variables considered in our study. Considering that member characteristics in different groups are heterogeneous in running ability and habit, absolute level- group records like aggregated running distance can be confounded by the group level heterogeneity, we use rate rather than the distance to describe group activity. Our dependent variable, $D E_{-} A C T_{i, t}$, the group activity performance, is operationalized as the group member exercise proportion percentage. The social comparison of a group are collective representations of acceptable and desirable group conducts. Here, social comparison includes two conducts- expertise influence ( NO_TOP3 $\left.3_{i, t-1}\right)$ and organizer influence $\left(N O_{-} C A P_{i, t-1}\right)$. The group organizer is the one who form, manage and operate the group and a group organizer is not necessary the member with highest running distance. The competitive climate (or level) (Wu et al 2015) between groups is the collective individual outcomes from a group to be contingent on the comparisons of their performance against that of the other group. The competitive climate is here depicted by $R A N K_{i, t-1}$ and $\triangle \mathrm{RANK}$. We measure the offline team building by the number of offline meetup events, which is recorded immediately after event initiation. There are two control variables- group age and sport index. The sport index is classified to 5 degrees and generally the lower the index, it is the safer and better to run outdoor.

Data description is in Table 2. All FIVs are smaller than 10 and the average of all VIFs is 3.48. Thus, there is no multicollinearity issue and we can incorporate all variables in our model.

\begin{tabular}{|c|c|c|c|c|c|c|}
\hline Variable & Min & $\operatorname{Max}$ & Mean & s.e. & $\mathrm{VIF}+$ & Tolerance \\
\hline$D E_{-} A C T_{i, t}$ & 0 & 70.14356 & 5.58865 & 6.80544 & ד- & -4 \\
\hline$N O \_T O P 3_{i, t-1}$ & 0 & 225.5167 & 28.84428 & 30.47314 & 3.29 & 0.304 \\
\hline$N O_{-} C A P_{i, t-1}$ & 0 & 160.36 & 8.057415 & 20.27662 & 1.60 & 0.623 \\
\hline$R A N K_{i, t-1}$ & 0 & 186 & 80.0718 & 47.21001 & 6.15 & 0.163 \\
\hline$\triangle \mathrm{RANK}$ & -150 & 155 & 0.8168283 & 27.09762 & 1.12 & 0.890 \\
\hline NO_OFFACT $T_{i, t-1}$ & 0 & 3 & 0.0128116 & .1386715 & 1.14 & 0.879 \\
\hline SPORT_INDEX $X_{t}$ & 6.714286 & 16.85714 & 11.83609 & 3.307581 & 7.35 & 0.136 \\
\hline$L A G_{-} G_{-} B U I L D_{i, t}=$ & 20 & 1454 & 782.7097 & 379.2633 & 5.83 & 0.171 \\
\hline
\end{tabular}

\section{Empirical Analysis Results and Findings}

\subsection{Baseline Model- The Fixed Effects}

According to the result of the Hausman test, the $C h i^{2}$ is $80.61(\mathrm{p}=0.000<0.05)$, there is sufficient evidence to reject the null that there is random effect.
Thus, we use the fixed effect model for the base model, which estimates the impacts of the within group social comparison and between group competitive climate on group activity, and the moderation model, which estimates the moderation effect of offline team working. Except for $D E \_A C T_{i t}$, which is a ratio and contain 0 values, we take natural $\log$ for all variables to void scale effect and heteroscedasticity.

The baseline model specification is:

$$
\begin{aligned}
& D E_{-} A C T_{i t}=\alpha_{0}+\alpha_{1} N O_{-} T O P 3_{i, t-1}+ \\
& \alpha_{2} N O_{-} C A P_{i, t-1}+\alpha_{3} R A N K_{i, t-1}+ \\
& \alpha_{4} \Delta \mathrm{RANK}_{i, t-1}+\text { ControlVariables }+\gamma_{i}+\omega_{i, t}
\end{aligned}
$$

where $\alpha_{0}$ is the constant, $\gamma_{i}$ is the unobserved timeinvariant individual effect and $\omega_{i, t}$ is the error term.

We summarize the fixed effect estimation in Table 3. For within-group comparison, both the role models' and the organizer's performance records improve the group activity participation. For the between-group competitive climate, the coefficient of group rank is significantly negative, and this indicates that the lower a group ranks in the previous period, the higher its current activity is. Meanwhile, the change of group rank significantly improves group activity. More specifically, within-group social comparison metricsNO_TOP3 and NO_CAP significantly improve $D E \_A C T$ by $0.034 * * *$ and $0.009 * * *$. Between-group competitive climate metrics $R A N K$ and $\triangle \mathrm{RANK}$ have significant impacts $(-0.018 * * *$ and $0.008 * * *)$ on $D E \_A C T$. Both the weather index and the team age have a negative impact on group activity participation and the negative consequences indicate that higher sport- index or less safe and comfortable weather is associated with less activity participation, and younger groups tend to be more exercise active.

Thus, the results support $\mathrm{H} 1 \mathrm{a}, \mathrm{H} 1 \mathrm{~b}, \mathrm{H} 2 \mathrm{a}$, and $\mathrm{H} 2 \mathrm{~b}$, and they are consistent with previous studies. As the consequences of upwards comparison, the top runner can be considered as an athlete role model by other group members and thus, the performance record of the role models can encourage and simulate other members to exercise more. As a result, group level exercise participation will be eventually improved. Organizers serve the group, participate in more group events, and their name and exercise performance will be more often exposed to other group members. Their behavior will be more influential. Additionally, the average running records for organizers is 8.057 kilometers per week. Compared with that of top performance members, the 8.057 distance is a relatively more accessible and achievable goal. Given the above two reasons, it is evident to find organizer's records have a 
significant boost in the overall group exercise participation.

\begin{tabular}{|c|c|c|c|c|}
\hline \multicolumn{2}{|c|}{ Table 3. Fixed effect analysis results ... } & \multicolumn{3}{|c|}{${ }^{* * *} \mathrm{p}<0.001,{ }^{* *} \mathrm{p}<0.01,{ }^{*} \mathrm{p}<0.05 *$} \\
\hline \multicolumn{2}{|l|}{ Variables } & Coef & s.e. & $\mathrm{p}$-value \\
\hline \multirow[t]{2}{*}{ Within-Group Social Comparison } & NO_TOP $3_{i, t-1}$ & $0.0343096 * * *$ & 0.0034438 & 0 \\
\hline & $N O_{-} C A P_{i, t-1}$ & $0.009102 * * *$ & 0.003367 & 0.007 \\
\hline \multirow[t]{2}{*}{ Between-Group Competitive Climate } & $\operatorname{RANK}_{i, t-1}$ & $-0.018086 * * *$ & 0.0018282 & 0 \\
\hline & $\triangle$ RANK & $0.0083756 * * *$ & 0.0016317 & 0 \\
\hline \multirow[t]{2}{*}{ Control Variables } & $S P O R T_{-} I N D E X_{t}$ & $-0.2483073 * * *+$ & 0.0124958 & 0 \\
\hline & $L A G_{-} G_{-} B U I L D_{i, t^{*}}$ & $-0.0017069 * * *+$ & 0.0005619 & 0.002 \\
\hline Constant & $\alpha$ & $10.24392 * * *$ & 0.4106652 & 0 \\
\hline
\end{tabular}

\subsection{Moderation Analysis}

To examine the moderating effect of group's team building on the impact of within-group comparison and between-group competitive climate on group activity, we incorporate the moderating relationships in the fixed effect model and the specification is

$D E_{-} A C T_{i t}=\beta_{0}+\beta_{1} N O \_T O P 3_{i, t-1}+$

$\beta_{2} N O_{-} C A P_{i, t-1}+\beta_{3} R A N K_{i, t-1}+\beta_{4} \Delta R A N K_{i, t-1}+$

$+\beta_{5} N O_{-} O F F A C T_{i, t-1}+$

$\beta_{6} N O_{-} O F F A C T_{i, t-1} N O_{-} T O P 3_{i, t-1}+$

$\beta_{7} N O_{-} O F F A C T_{i, t-1} N O_{-} C A P_{i, t-1}+$

$\beta_{8} N O_{-} O F F A C T_{i, t-1} R A N K_{i, t-1}+$

$\beta_{9} N O_{-} O F F A C T_{i, t-1} \triangle R A N K_{i, t-1}+$

Controlvariables $+\mu_{i}+\varepsilon_{i, t}$

$D E_{-} A C T_{i t}=\beta_{0}+\beta_{1} N O_{-} T O P 3_{i, t-1}+$

$\beta_{2} N O_{-} C A P_{i, t-1}+\beta_{3} R A N K_{i, t-1}+\beta_{4} \Delta R A N K_{i, t-1}+$

$+\beta_{5} N O_{-} O F F A C T_{i, t-1}+$

$\beta_{6} N O_{-} O F F A C T_{i, t-1} N O_{-} T O P 3_{i, t-1}+$

$\beta_{7} N O_{-} O F F A C T_{i, t-1} N O_{-} C A P_{i, t-1}+$

$\beta_{8} N O_{-} O F F A C T_{i, t-1} R A N K_{i, t-1}+$

$\beta_{9} N O_{-} O F F A C T_{i, t-1} \Delta R A N K_{i, t-1}+$

ControlVariables $+\mu_{i}+\varepsilon_{i, t}$

where $\beta_{0}$ is the constant, the moderators $N O_{-} P I C_{i, t-1}$ is the aggregated the number of offline meetup activities, $\mu_{i}$ is the unobserved time-invariant individual effect and $\varepsilon_{i, t}$ is the error term.

\begin{tabular}{|c|c|c|c|c|}
\hline \multicolumn{2}{|l|}{ Variable } & \multirow{2}{*}{\begin{tabular}{|l|} 
Coef \\
$0.034^{* * *}$ \\
\end{tabular}} & \multirow{2}{*}{$\begin{array}{l}\text { s.e. } \\
0.003\end{array}$} & \multirow{2}{*}{$\begin{array}{c}\text { p-value } \\
0.000\end{array}$} \\
\hline Within-Group Social- & $N O_{-} T O P 3_{i, t-1}$ & & & \\
\hline Comparison & $N O_{-} C A P_{i, t-1}$ & $0.311 * * *$ & 0.047 & 0.000 \\
\hline \multirow{2}{*}{$\begin{array}{l}\text { Between-Group } \\
\text { Competitive Climate }\end{array}$} & $R A N K_{i, t-1}$ & $-0.017 * * *$ & 0.001 & 0.000 \\
\hline & $\triangle \mathrm{RANK}$ & $0.008^{* * *}$ & 0.001 & 0.000 \\
\hline Offline Team Building & NO_OFFACT $T_{i, t-1}$ & $2.949 * * *$ & 1.101 & 0.007 \\
\hline \multirow{4}{*}{ Moderators } & NO_OFFACT $T_{i, t-1} \times N O \_T O P 3_{i, t-1}$ & -0.007 & 0.008 & 0.378 \\
\hline & NO_OFFACT $T_{i, t-1} \times N O \_C A P_{i, t-1}$ & -0.246 & 0.189 & 0.194 \\
\hline & NO_OFFACT $T_{i, t-1} \times R R A N K_{i, t-1}$ & $-0.040^{* *}$ & 0.020 & 0.043 \\
\hline & NO_OFFACT $T_{i, t-1} \times \triangle \mathrm{RANK}$ & $0.046 * *$ & 0.023 & 0.043 \\
\hline \multirow[t]{2}{*}{ Control variables } & $S P O R T_{-} I N D E X_{t}$ & $-0.242 * * *$ & 0.012 & 0.000 \\
\hline & $L A G_{-} G_{-} B U I L D_{i, t^{*}}$ & $-0.001 * * *$ & 0.001 & 0.002 \\
\hline \multicolumn{2}{|l|}{ Constant } & $9.935 * * *$ & 0.412 & 0.000 \\
\hline
\end{tabular}

Table 4 summarizes the results. More specifically, NO_OFFACT has a significant positive impact $\left(2.949^{* * *}\right)$ on $D E_{-} A C T$, and it has a significant positively moderation impact $\left(-0.04 * * *\right.$ and $\left.0.046^{* *}\right)$ on the relationship between the between-group competitive climate metrics and the group participation and $\mathrm{H} 3 \mathrm{~b}$ are supported. However, the interactions between offline team building and within-group social comparison are not significant, and $\mathrm{H} 3 \mathrm{a}$ is not supported. These two distinct interaction effects within and between groups are consequences of team buildings and are consistent with Carron 1998. According to the Team Working Theory by Tuckman 1995, team building activities can improve the sense of cohesion, social ties, and bonding between group members. Under our research setting- Fitness apps, most of the offline teambuilding activities are not limited to exercise or fitness meetups. Teambuilding can also be social and entertainment events. Through the meetup social parties and casual social interactions, the individual level workout competition can be diminished by bonding and social support, or even friendships between group members. Friends' running records may not necessarily be a target to be compared with and to be broken through, and group members will lose to the motive to compete with each other as the intimacy grows. On the other side, as the cohesion improves though offline team building activities, members focus more on group performance and have a stronger sense of having responsibility for group task outcomes (Widmeyer and Williams 1991). Due to the awareness of the group honor, there will be incentives to exercise and participate more to keep the group's high rank or to sustain a positive change, or to improve group rank from a low score or to minimize a negative turn. Thus, the interaction between offline activities and competitive climate between different groups are significant.

Besides the interesting findings of moderation effects, the main effects of within-group social comparison and between-group competitive climates, and the effects of control variables on group activity participation are all consistent with the results of the baseline model.

\section{Validation and Robustness Check}

We conduct several additional tests to validate the robustness of the results.

\subsection{Reversal Causality Check through the Panel VAR Granger Causality Test}

If there is reversal causality, the group activity participation rate would dynamically impact on the within-group social comparison and between-group 
competitive climate. To avoid the threat of reversal causality to the internal validity of our empirical findings, we conduct the Granger causality test procedure in the Panel Vector Auto-Regression analysis. Table 5 shows the Granger test results for the baseline model. Based on accumulated impacts between covariates, the results illustrate that both within and between group social comparisons significantly Granger cause the group activity participation rate, and meanwhile, there is no significant reversal Granger causality. Through this test, we can exclude the threat of reversal causality to the internal validity of the results of our baseline model. Thereby, the findings and support for the first two hypotheses are validated.

Similarly, we conduct the PVAR Granger test for the moderation analysis findings by entering the moderators in the PVAR estimation, and test results are summarized in Table 6 . The interactions between offline team building activities and between and within-group social comparisons significantly Granger cause group activity participation, and there is no reversal causality either. This test also strengthens the validity of the findings of the moderation analysis.

\begin{tabular}{|c|c|c|c|c|c|c|c|c|c|c|}
\hline \multicolumn{11}{|c|}{ Table 5. Panel VAR-Granger Causality Wald Test- } \\
\hline \multicolumn{11}{|c|}{ Ho: Excluded variable does not Granger-cause Equation variable } \\
\hline \multirow{2}{*}{\multicolumn{11}{|c|}{ Ha: Excluded variable Granger-causes Equation variable }} \\
\hline \multirow{2}{*}{\multicolumn{4}{|c|}{$\begin{array}{l}\text { Chi2 (Significant Level) } \\
\text { Causality Validation }\end{array}$}} & \multirow{2}{*}{\multicolumn{7}{|c|}{ Reverse Effect Check }} \\
\hline & & & & & & & & & & \\
\hline Response to & \multicolumn{3}{|c|}{$\begin{array}{l}\text { Group Activity } \\
\text { Participation Rate: de_act }\end{array}$} & \multirow{2}{*}{\multicolumn{2}{|c|}{ Response to }} & \multirow{2}{*}{\multicolumn{2}{|c|}{$\begin{array}{l}\text { Within-Group } \\
\text { Social Comparison }\end{array}$}} & \multirow{2}{*}{\multicolumn{3}{|c|}{$\begin{array}{l}\text { Between-Grou } \\
\text { Competitive } \\
\text { Climate }\end{array}$}} \\
\hline Within-Group & \multirow{2}{*}{$\begin{array}{l}\text { no_top3 } \\
\text { no_cap }\end{array}$} & \multicolumn{2}{|l|}{$5.124 * *$} & & & & & & & \\
\hline Social Comparison $n$ & & 2.994* & & \multirow{2}{*}{\multicolumn{2}{|c|}{$\begin{array}{l}\text { Group Activity } \\
\text { Participation : }\end{array}$}} & no_top3 & no_cap & rank & & rankc \\
\hline $\begin{array}{l}\text {-Group } \\
\text { tive }\end{array}$ & & $\begin{array}{r}24.28^{* * *} \\
4.627 * *\end{array}$ & & & & 0.906 & 2.11 & & 723 & 0.72 \\
\hline \multicolumn{11}{|c|}{ Table 6. Panel VAR-Granger Causality Wald Test-Moderation Model Findings (Chi2 (Significant Leve } \\
\hline \multicolumn{3}{|c|}{ Causality Validation } & \multicolumn{8}{|c|}{ Reverse Effect Check } \\
\hline Response to & & Group & \multirow{2}{*}{\multicolumn{2}{|c|}{ Response to }} & \multirow{2}{*}{\multicolumn{2}{|c|}{$\begin{array}{l}\text { Within-Group Social } \\
\text { Comparison x Offline Team } \\
\text { Building Activities }\end{array}$}} & \multirow{2}{*}{\multicolumn{4}{|c|}{$\begin{array}{l}\text { Between-Group Competit } \\
\text { Climate } \mathrm{x} \text { Offline Team } \\
\text { Building Activities }\end{array}$}} \\
\hline $\begin{array}{l}\text { Within-Group Social } \\
\text { Comparison x Offline Team }\end{array}$ & n offact_top3 & $0.313^{*}$ & & & & & & & & \\
\hline Building Activities & offact_cap & $4.885 * *$ & \multirow{2}{*}{\multicolumn{2}{|c|}{$\begin{array}{c}\text { Group } \\
\text { Activity } \\
\text { Participation }\end{array}$}} & offact_top3 & offact_cap & & t_rank & & t_ran \\
\hline $\begin{array}{l}\text { Between-Group Competitive } \\
\text { Climate x Offline Team } \\
\text { Building Activities }\end{array}$ & $\begin{array}{l}\text { offact_rank } \\
\text { offact_rankc }\end{array}$ & $\begin{array}{r}6.326^{*} \\
0.963\end{array}$ & & & 0.521 & 0.137 & & 055 & & 584 \\
\hline
\end{tabular}

5.2 Alternative Measure of Offline Team Building Activates

We collect the number of aggregated number of pictures of offline activities from another panel of the fitness app. Besides initiating and recording offline meetup events, the app also allows users to upload pictures later on. Only recent event's information (the weekly number of offline meetup events) is shown on the group board, yet, all past event pictures are listed on the board. More specifically, given our research setting, the number of offline activities listed on the group information board will be refreshed by the fitness app weekly and any historical offline activities earlier than a week ago are not accessible to group members. Thereby, we consider the number of offline activities as the short-term measure of offline team building. Since all previous meetup event photos can be accessible and observable by all group members, we consider the total number of activities pictures as a longer-term measurement and representation of offline team building than the number of offline activities. We expect that this longer-term offline team building measure (in terms of the total number of activities pictures), denoted as $N O_{-} P I C_{i, t}$ for group $i$ at time $t$, has moderating impacts, which would be consistent with that of NO_OFFACT $T_{i, t}$. That is $N_{-} P_{P} I C_{i, t}$ can significantly moderate the effects of within-group social comparison and the effects of between-group competitive climates on the group activity performance. We estimate the moderation model by using NO_OFFACT $T_{i, t}$ and summarize the results in Table 7.

Table 7. Offline Team Building Moderation With Fixed Effect Analysis Results-Alternative Measure

*** $\mathrm{p}<0.001,{ }^{* *} \mathrm{p}<0.01,{ }^{*} \mathrm{p}<0.05$ (Unit=Percentage)

\begin{tabular}{|c|c|c|c|c|}
\hline Variable & & Coef & s.e. & $p$-value \\
\hline \multirow{2}{*}{$\begin{array}{l}\text { Within-Group Social- } \\
\text { Comparison }\end{array}$} & no_top3 & $3.4 * * *$ & 0.004 & 0 \\
\hline & no_cap & $28.7^{* * * *}$ & 0.049 & 0 \\
\hline \multirow{2}{*}{$\begin{array}{l}\text { Between-Group } \\
\text { Competitive Climate }\end{array}$} & rank & $-1.3 * * *$ & 0.002 & 0 \\
\hline & rankc & $0.5^{* * *}$ & 0.002 & 0.004 \\
\hline Offline Team Building & no_pic & $45.2^{* * *}$ & 0.167 & 0.007 \\
\hline \multirow[t]{4}{*}{ Moderators } & no_pic x no_top3 & 0.1 & 0.002 & 0.54 \\
\hline & no_pic x no_cap & 0.1 & 0.001 & 0.81 \\
\hline & no_pic $\mathrm{x}$ rank & $-0.5^{* * *}$ & 0.002 & 0 \\
\hline & no_pic x rankc & $0.4 * * *$ & 0.002 & 0.009 \\
\hline \multirow[t]{2}{*}{ Controls } & sport_index & $-23.9^{* * * *}$ & 0.013 & 0 \\
\hline & lag_g_build & $-0.2 * * *$ & 0.001 & 0 \\
\hline
\end{tabular}

We find the long-term measure of offline team working can significantly moderate the impacts of between-group competitive climates on group exercise participation. However, the moderation effects on the relationship between within-group social comparison and the group exercise participation are nonsignificant. These results are consistent with the moderation effects of the short-term measure of offline team building and again support $\mathrm{H} 3 \mathrm{~b}$. The main effects of within-group social comparison and between-group competitive climate are consistent with that of the results of using the number of offline activities. Thereby, hypothesis one and two are supported by the results alternative measure as well.

\section{Additional Analysis}

\subsection{Dynamic Effects Analysis through Panel VAR IRF and FEVD}

To study the dynamics association between withingroup social comparison, between-group competitive climate and the group activity participation, we 
conduct a comprehensive Panel VAR analysis. The Panel VAR specification for the baseline model is:

$$
Y_{i t}=\sum_{k=1}^{p} A_{k} Y_{i t-k}+B X_{i t}+e_{i t}
$$

where

$$
\boldsymbol{Y}_{i t}=\left(\begin{array}{c}
D E_{-} A C T_{i, t} \\
N O_{-} T O P 3_{i, t} \\
N O_{-} C A P_{i, t} \\
R A N K_{i, t} \\
\Delta R A N K_{i, t}
\end{array}\right)
$$

$\boldsymbol{X}_{i t}=\left(\begin{array}{l}S P O R T_{-} I N D E X_{t} \\ L A G_{-} G_{-} B U I L D_{i, t}\end{array}\right), \mathrm{i} \in\{1,2, \ldots N\}, \mathrm{t} \in\{1,2, \ldots T\}$.

$\mathrm{N}$ is the number of groups and $\mathrm{T}$ is the time span. $\boldsymbol{Y}_{\boldsymbol{i t}}$ is a vector of endogenous covariates. $\boldsymbol{X}_{\boldsymbol{i t}}$ is a vector of control variables. The matrix $A$ and matrix $B$ are parameters to be estimated through Panel VAR model. Here the idiosyncratic errors $e_{i t}$ are assumed to have stable trend s.t. $E\left[e_{i t}\right]=0, E\left[e_{i t}^{\prime} e_{i t}\right]=\Sigma$, and $E\left[e_{i t}^{\prime} e_{i s}\right]=0, \forall t \neq s$. Based on Love (2015), Hayakawa (2015), Canova \& Ciccarelli (2013), and Holtz-Eakin et al. (1988), we take Helmert transformation for all covariates to avoid heteroscedasticity and to remove scale effect and following these PVAR analysis, we have the following procedure: 1). Pre-estimation unit root test for stability check. 2). Select optimal lag terms. 3) GMM estimation. 4). Eigenvalue test for IRF estimates stability check. 5). Granger causality test for causal and reverse effect. 6). Impulse response function (IRF). 7). Forecast error variance decomposition (FEVD). All covariates pass the ADF test and based on the minimized information criteria (MQIC* $=-63.526$ and J-Statistics $*=47.025)$ and the maximal determination coefficient (0.999), the optimal highest order is 2 . After checking causality validity and reverse effects through the Granger test and given the parameters 'estimates (will be provided if requested) for all lag terms, we generate the impulse response functions (IRF). The impulse response function $\Phi_{i}$ can be captured by the re-shaping the reduced form Panel VAR model to infinite vector moving average form and the VMA parameters $\Theta_{i}=\left\{\begin{array}{c}I_{k}, i=0 \\ \sum_{j=1}^{i} \varphi_{t-j} A_{j}, i=1,2 \ldots .\end{array}\right.$ The IRF with estimated coefficients can gauge the net effects of one unit unexpected change in between/ within group social comparisons metrics $i$ on $D E_{-} A C T_{i, t}$ at time t. Standard errors are generated by Monte Carlo simulation with 500 repetition and coefficients' significance is tested by 0.95 confidence interval. We summarize the combined IRF graphs of key covariates in Figure 2. Based on innovation simulation, IRF illustrates how many unit y-axis metric changes given one unit change of $\mathrm{x}$ axis metric. The dotted lines form a cone, which represents the significance level. Here, the range includes two standard deviations. In Table 8, we summarize the immediate predictive elasticity and the accumulated value that combines all significant

\begin{tabular}{|c|c|c|c|}
\hline & \multicolumn{3}{|c|}{ Group Activity Participation Rate: de_act } \\
\hline & & Immediate & Accumulated \\
\hline \multirow[t]{2}{*}{ Within-Group Social-Comparison } & no_top3 & $0.13^{*}$ & $1.15^{* *}$ \\
\hline & no_cap & -0.03 & $0.74^{*}$ \\
\hline \multirow[t]{2}{*}{ Between-Group Competitive Climate } & rank & $-0.03^{*}$ & $-0.77 * *$ \\
\hline & rankc & 0.12 & $10.58 * * *$ \\
\hline
\end{tabular}
effects across the forecasting periods from each IRF.

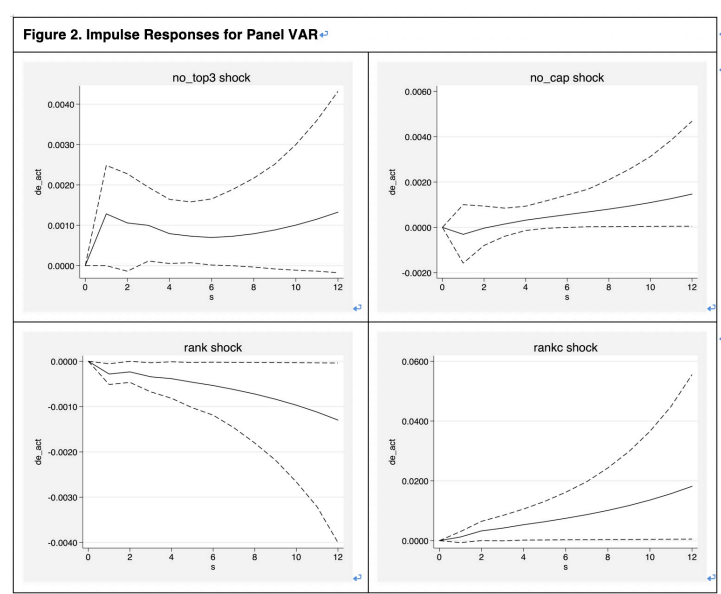

The IRF results illustrate that role-model performance records and the drop of group rank weakly improve the immediate value of group activity participation rate by 0.0013 and 0.003 units. While there are few significant and immediate impacts, all of within-group social comparison and between-group competitive climate metrics have significant predictive relationships with group activity participation rate. More specifically, one unit $N O \_T O P 3_{i, t}, N O \_C A P_{i, t}, R A N K_{i, t}$ and $\triangle \mathrm{RANK}$ (drop) can increase $0.0115,0.0074,0.0077$ and 0.1058 units of group activity participation respectively. Based on the estimated PVAR parameters, we derive the forecast- error- variance- decomposition (FEVD) estimates to isolate the contribution of within and between group social comparison metrics. According to Abrigo and Love 2015, the h-step ahead forecasterror is described as $D E_{-} A C T_{i, t+h}-E\left[D E_{-} A C T_{i, t+h}\right]=\sum_{i=0}^{h-1} e_{i,(t+h-i)} \Theta_{i}$. After summating the normalized relative to the 10 -period ahead FEVDs, the relative predictive values of $N O \_T O P 3_{i, t}, N O_{-} C A P_{i, t}, R A N K_{i, t}$ and $\triangle$ RANK (drop) are $0.273 \%, 0.012 \%, 2.137 \%$ and $0.019 \%$ respectively.

Patterns in the results of PVAR analysis are consistent the findings of the fixed effect estimation. Besides, providing dynamic impacts of covariates, PVAR also further validate our empirical results in previous sections and further support our hypotheses about the main effects between group-level social comparisons and group participation. 


\subsection{Heterogeneous Effects of Top three members and Different Weathers}

We enter the performance records of top 1, 2 and 3 members into the baseline fixed effect model and find that the impacts of first and second top performance members on group activity participation are not significant (0.067 and 0.079). Yet, the impact of the third top performance member is significant $\left(0.157^{* *}\right)$. According to the descriptive statistics of top 3 members' performance, the average running distance of top 1 member is 44.16 kilometers per week, top 2 is 22.79 and top 3 is 17.46 . Through pair comparison, we find the top 3 member's performance is significant lower than top 2's ( $\mathrm{p}=0.012)$. Only the top 3 member's performance has significant impact on group participation rate may because that the athletic ability of the top-3 member is considered to be more related to that of average group members and thus top-3 members' records are considered to be relatively more comparable and reachable upwards role models.

Additionally, by collecting more detailed weather data from the fitness app, we separate the SPORT_INDEX $X_{t}$ to four weather indicators such as high temperature, low temperature, wind force and extreme weather, and then we enter these weather indicators to the baseline model. We find that only high temperature weather and extreme weather significantly impact on group participation $(-0.031 * *,-0.209 * * *)$.

\section{Implications}

This study is intended to examine the impacts of within group social comparison and between-group competitive climate on group exercise participation as well as how the offline team building activities interact with the main effects. Our results show that both the within-group social comparison and the between-group competitive climates significantly improve the group exercise participation. However, the offline team building has a significant positively moderation impact only on the relationship between the between-group competitive climate metrics and group participation.

We have four theoretical implications. First, we extend the social comparison theory to the group level and examine the role of "group" by differentiating the social comparison within group members and the comparison or competition between different groups. Second, in previous literature, group identity is examined as an environmental factor and measured mainly through surveying people's perceived belongingness. Our study provides direct empirical evidence to quantify the distinct consequences of within and between group social comparisons and competition. Third, there are few previous research studying the user's offline social interactions and their impacts on user's online retention and exercise participation. By combining the Teamwork theory, we explain distinctive moderating effects of offline team building activities on the effects of within-group social comparison and between-group competitive climate. Fourth, we extend the generalization of the Teamwork theory from a working setting in the human resource field to an online-hobby-community setting in the IS field by verifying its central propositions through rich empirical evidence.

This study also has two managerial implications for fitness app developers and managers. First, our findings can help developers understand the role and importance of "group" and group-level social comparison. Based on our results, both within and between group comparison and competition can have a salient boost in group user's activity participation and retention. We suggest developers allocate more rewards for desired group outcomes and reinforce users' awareness of the cohesion of the group when designing group level gamification mechanism. Second, our results demonstrate that offline team building activities only significantly moderate the effects of between-group competitive climates on group exercise participation. Motivated such we suggest managers initiate offline events, which can include more group competitions to trigger group members' motive to exercise and participate more for the honor of groups.

\section{Conclusion}

This study investigates how within-group social comparison and between-group competitive climates affect group member activities, and how offline team building activities moderate these effects. Our findings reveal the significance of the role of groups and the importance of offline activities in strengthening that role. Future research can build more systematic models to uncover how offline social interaction and user behaviors shape the growth of the online communities and their members' online behaviors.

\section{References}

[1] Bock, G. W., \& Kim, Y. G. (2002). Breaking the myths of rewards: An exploratory study of attitudes about knowledge sharing. Information Resources Management Journal (IRMJ), 15(2), 14-21. [2] Breukelen WV, Leeden RVD, Wesselius W, Hoes M 2012. Differential treatment within sports teams, leader-member (coach-player) exchange quality, team atmosphere, and team performance. J Organ Behav, 33(1): 43-63. 
[3] Brown, D. J., D. L. Ferris, D. Heller and L. M. Keeping (2007). "Antecedents and consequences of the frequency of upward and downward social comparisons at work." Organizational Behavior and Human Decision Processes 102(1): 59-75.

[4] Buunk, B. P., Collins, R. L., Taylor, S. E., VanYperen, N. W., \& Dakof, G. A. (1990). The affective consequences of social comparison: either direction has its ups and downs. Journal of personality and social psychology, 59(6), 1238.

[5] Carron, A.V. (1988). Group dynamics in sport. London, ON: Sports Dynamics.

[6] Carron, A.V., \& Spink, K.S. (1992). Internal consistency of the Group Environment Questionnaire modified for an exercise setting. Perceptual and Motor Skills, 74, 304-306.

[7] Cavallo, D. N., Tate, D. F., Ries, A. V., Brown, J. D., DeVellis, R. F., \& Ammerman, A. S. (2012). A social media-based physical activity intervention: A randomized controlled trial. American Journal of Preventive Medicine, 43(5), 527-532. doi:

10.1016/j.amepre.2012.07.019

[8] Festinger L (1954). "A theory of social comparison processes". Human Relations. 7 (2): 117-140.

doi:10.1177/001872675400700202.

[9] Fisher, R. J., \& Ackerman, D. (1998). The effects of recognition and group need on volunteerism: A social norm perspective. Journal of consumer research, 25(3), 262-275.

[10] Garcia, S. M., Tor, A., \& Schiff, T. M. (2013). The psychology of competition: A social comparison perspective. Perspectives on Psychological Science, 8(6), 634-650

[11] Kelman, H. C. (1958). "Compliance, Identification, and Internalization: Three Processes of Attitude Change." Journal of Conflict Resolution 2(1): 51-60.

[12] Mussweiler, T., \& Strack, F. (2000). The "relative self": Informational and judgmental consequences of comparative self-evaluation. Journal of Personality and Social Psychology, 79(1), 23-38.

[13] Mussweiler, T., Ruter, K., \& Epstude, K. (2004). The man who wasn't there: Subliminal social comparison standards influence self-evaluation. Journal of Experimental SocialPsychology, 40, 689696.

[14] Munson, S. A., \& Consolvo, S. (2012, May). Exploring goal-setting, rewards, self-monitoring, and sharing to motivate physical activity. In 2012 6th international conference on pervasive computing technologies for healthcare (pervasive health) and workshops (pp. 25-32). IEEE.

[15] Richardson, C.R., Buis, L.R., Janney, A.W., Goodrich, D.E., Sen, A., Hess, M.L., Mehari, K.S., Fortlage, L.

[16] A., Resnick, P.J., Zikmund-Fisher, B.J., Strecher, V.J., and Piette, J.D. 2010. "An Online Community Improves Adherence in an Internet-Mediated Walking Program. Part 1: Results of a Randomized Controlled Trial," Journal of Medical Internet Research (12:4), pp. 138-153.

[17] Sepehr, S., and Head, M. 2011. "The Role of Competitiveness in the Cognitive Absorption of Video Games," The 10th Pre-ICIS Annual Workshop on HCI Research in MIS.

[18] Singer, E. (1981). Reference groups and social evaluations. In Rosenberg, M., Turner, R. H. (Eds.), Social psychology: Sociological perspectives (pp. 6693). New York: Basic Books.

[19] Sonders and Ana L. (2016). These fitness app statistics show what's going right (and wrong) for Fitbit. SurveyMonkey Intelligence

[20] Tuckman, B. W. (1965). Developmental sequence in small groups. Psychological bulletin, 63(6), 384.

Widmeyer, W. N., \& Williams, J. M. (1991).

Predicting Cohesion in a Coacting Sport. Small Group Research, 22(4), 548-570.

https://doi.org/10.1177/1046496491224007

[21] Wu, Y., A. Kankanhalli and K. Huang (2015).

"Gamification in Fitness Apps: How Do Leaderboards Influence Exercise?".

[22] Zhou, Y., A. Kankanhalli and K. W. Huang (2016). Effects of Fitness Applications with SNS: How Do They Influence Physical Activity. International Conference on Information Systems. 